\title{
Laboratório virtual de Física: Gravitação
}

\author{
Nascimento, M. L. F. ; Campana V. F. ${ }^{2}$; Gonçalves, A. O. O. ${ }^{3}$; Prado, R. T. ${ }^{4}$ \\ 1 Curso de Graduação em Sistemas de Informação, Faculdade do Centro Leste - UCL, Serra, ES, Brasil \\ 2 Curso de Graduação em Sistemas de Informação, Faculdade do Centro Leste - UCL, Serra, ES, Brasil \\ 3 Núcleo Básico de Engenharia, Faculdade do Centro Leste - UCL, Serra, ES, Brasil \\ 4 Núcleo Básico de Engenharia, Faculdade do Centro Leste - UCL, Serra, ES, Brasil
}

\begin{abstract}
Resumo
Este artigo apresenta a construção de um laboratório virtual que permite a visualização de fenômenos associados à gravitação no sistema solar a partir de simulação em um ambiente computacional com gráficos em 3D no intuito de melhorar o processo de ensino e aprendizagem de Física através da utilização de simulações animadas como recurso complementar para professores de Física do ensino médio. $\mathrm{O}$ trabalho apresentado aqui é fruto de um projeto de iniciação científica que envolveu estudantes e educadores tanto no processo de especificação da tecnologia utilizada na implementação do software, quanto nos requisitos de funcionalidades da ferramenta, sendo validada por especialistas na área.
\end{abstract}

Keywords (Palavras chaves): Simulação, Gravitação, Ambiente Computacional, Aprendizagem.

\section{Introdução}

Muitos alunos apresentam dificuldades durante 0 processo de aprendizagem de Física quando se trata da compreensão dos fenômenos físicos, sendo que isso muitas vezes ocorre devido à metodologia adotada e que pode ser melhorada com o uso diversificado do computador no ensino da Física, algo que vem sendo feito em toda a área das Ciências Exatas. [1] Diversos grandes centros de pesquisas avançadas, como o "PhET.colorado"[2], utilizam computadores com esses fins para estudos de cosmologias observacionais, comportamentos atômicos e ligações, estruturas de materiais e fissuras e criação de aplicativos que facilitem o aprendizado e a visualização de fenômenos, através de laboratórios virtuais [3].

Os laboratórios virtuais podem ser utilizados para a visualização de fenômenos provenientes de interações que não são triviais de se criar em laboratórios reais, como movimento de partículas microscópicas e interação entre os planetas do sistema solar. $O$ estudo da interação entre os planetas é objeto de estudo da humanidade há milhares de anos e é amplamente discutido em livros didáticos, inclusive de ensino médio, porém sem a visualização experimental que carece de equipamentos e tempo para a confirmação da teoria estudada [4]. Utilizar um laboratório virtual aumenta a possibilidade de uma discussão mais ampla desses fenômenos físicos através da visualização de simulações, inclusive, modificando suas condições pelo usuário (aprendiz ou educador) possibilitando novas experimentações melhorando a compreensão dos conceitos envolvidos.

\section{Materiais e Métodos}

Uma pesquisa inicial foi feita das diversas ferramentas de simulação disponíveis para realização de simulação de fenômenos físicos, priorizando software gratuito, alem de ambientes de desenvolvimento, e pode-se notar certa carência no tema gravitação levando assim à construção do software.

Para a implementação do software foi utilizado o ambiente de desenvolvimento Blander3D em sua versão 2.70 e os scripts que controlam os movimentos nas animações foram escritos em python, que é a linguagem de programação padrão dessa versão do Blender3D. As funcionalidades do software foram fundamentadas nos seguintes princípios físicos sobre Gravitação Universal: Os planetas orbitam em torno do Sol descrevendo trajetórias elípticas, com o Sol ocupando um dos focos da elipse ( $1^{a}$ Lei de Kepler: Lei das órbitas).

A linha que une o planeta ao Sol varre áreas iguais em tempos iguais. (2 $2^{\mathrm{a}}$ Lei de Kepler: Lei das áreas) [5]

A razão entre o quadrado do período de translação e 0 cubo da distância média ao Sol é uma constante. ( $3^{\mathrm{a}}$ Lei de Kepler: Lei dos Períodos) [5].

Fica mais claro se expressarmos esta lei em uma fórmula:

$$
\frac{T^{2}}{d^{3}}=\frac{4 \pi^{2}}{G M}
$$

Onde, $\mathrm{M}$ é a massa solar $=1,9 \times 1030 \mathrm{~kg}$ e $\mathrm{G}$ é chamada de constante universal da gravitação e vale $6,67 \times 10-11 \mathrm{~N} . \mathrm{m} 2 / \mathrm{kg} 2$. 
Newton propôs a seguinte lei, que ficou conhecida como a Lei Universal da Gravitação:

Matéria atrai matéria na razão direta do produto de suas massas e na razão inversa do quadrado da distância que as separa.

Matematicamente expressamos com a seguinte fórmula:

$$
F=G \frac{m M}{d^{2}}
$$

Onde $\mathrm{m}$ e $\mathrm{M}$ são as massas e d é a distância entre os centros dos corpos.

\section{Resultados}

A primeira versão da ferramenta já está funcional e em processo de avaliação pelos Educadores e Físicos envolvidos no projeto e será incorporado como material didático na disciplina de Física da turma de primeiro ano do ensino médio da escola piloto para a validação mais concreta da contribuição que o recurso computacional pode oferecer.

A seguir são apresentadas algumas telas do software em execução. Disponível no site do projeto [6]
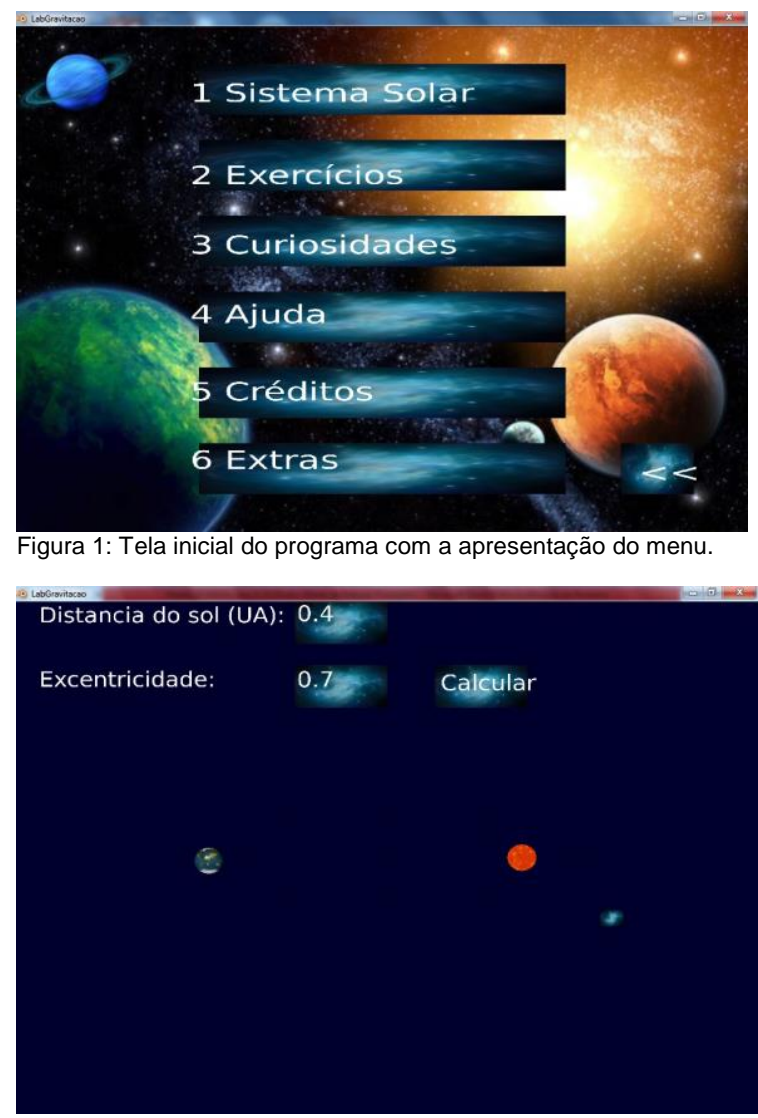

Figura 2: Simulação de um corpo girando em torno do sol.

Alguns exercícios frequentemente trabalhados nos materiais didáticos poderão ser experimentados na ferramenta buscando facilitar a compreensão dos conceitos de forma mais visível e lúdica, tornando o processo de aprendizagem divertido, atraindo a atenção dos estudantes. Algo que pode ser visto na Figura 2.

\section{Conclusões e trabalhos futuros}

Apesar de ainda não ter sido realizada a experimentação da ferramenta na sala de aula da escola piloto até a presente data deste artigo, o professor que irá incorporar experimentalmente o recurso em suas aulas sinalizou positivamente sobre a possibilidade de melhoria do processo de ensino aprendizagem.

Futuramente essas simulações podem ser incorporadas em outros ambientes como jogos educacionais, expandindo mais o contexto de aplicações, promovendo o aprendizado de Física além do cenário escolar.

\section{Agradecimentos}

Os autores agradecem a FAPES pelo apoio financeiro e demais colegas de trabalho que estão sempre dispostos a colaborar.

\section{Referências}

[1] FIOLHAIS, C.; TRINDADE, J. Física no computador: o computador como uma ferramenta no ensino e na aprendizagem das ciências físicas. Disponivel em: http://www.scielo.br/scielo.php?script=sci_arttext\&pid=S 1806-11172003000300002. Acesso em: abril de 2013.

[2] PhET's End of School Campaign. Interactive Simulations. Disponivel em: http://phet.colorado.edu/pt_BR/simulations/category/b y-level/university. Acesso em: abril de 2013.

[3] Ciência à mão. Abordagens Epistemologicas no Ensino de Fisica: a Cosmologia Como Tema Motivador. Disponível

em: http://www.cienciamao.usp.br/tudo/busca.php?key=abo rdagens $\% 20$ epistemologicas $\% 20$ no $\% 20$ ensino $\% 20$ de \%20fisica:\%20a\%20cosmologia\%20como\%20tema\%2 Omotivador\&tipo=atividades. Acesso em: abril de 2013.

[4] HALLIDAY D.; RESNICK R. e WALKER J. Fundamentos de Física: gravitação, ondas e termodinâmica. Volume 2. $8^{\mathrm{a}}$ edição. Editora LTC, 2009.

[5] MOURA, S, C. Física para o Ensino Médio: Gravitação, Eletromagnetismo e Física Moderna. Porto Alegre : EDIPUCRS, 2011.

[6] Projeto Gravitação. Laboratório Virtual de Física: Gravitação. Disponível em: https://ww1.ucl.br/sistemas/LabGravitacao/SitePages/P \%C3\%A1gina\%20Inicial.aspx Acesso em: maio de 2014. 